\title{
A randomized double blind controlled trial comparing Ibuprofen versus Ibuprofen plus Acetaminophen plus Caffeine for pain control after impacted third molar surgery*
}

\author{
Shahrokh Raisian, Hamid Reza Fallahi", Leila Badakhshan, Dana Zandian \\ Oral and Maxillofacial Surgery, Imam Khomeini Medical Center, Department of Oral and Maxillofacial Surgery, Jondishapour Uni- \\ versity of Medical Sciences, Ahvaz, Iran. \\ Email: " Raisianshahrokh@yahoo.com, Dr.hamidrezafallahi@gmail.com
}

Received 29 March 2012; revised 19 April 2012; accepted 7 May 2012

\begin{abstract}
Non-steroidal anti-inflammatory drugs like Ibuprofen alleviate mild to moderate postoperative pain caused by the third molar extractions. Moreover, Acetaminophen is a non-opioid analgesic with antipyretic properties, effective in relieving mild to moderate pain. On the other hand, recent studies have demonstrated that Caffeine also acts as an analgesic adjuvant when combined with Acetaminophen, Aspirin, or their mixture. The objective of study is to compare the efficacy of a combination of Ibuprofen $200 \mathrm{mg}$ and Acetaminophen $\mathbf{3 2 5} \mathrm{mg}$ plus Caffeine $\mathbf{4 0}$ mg with Ibuprofen $400 \mathrm{mg}$ alone for relieving the pain after surgical removal of impacted mandibular third molar. 80 adult patients (56 females, 24 males) were randomly placed into two groups. Preoperative pain recorded prior to the surgery and compare with patients' pain after the operation. According to findings, there was no significant relationship between preoperative and postoperative pain ( $P$ value $>0.05$ ) and also between surgical trauma and postoperative pain ( $P$ value $>0.05)$. The mean pain showed a slight numerical superiority for the group which used Ibuprofen plus Acetaminophen plus Caffeine especially 3hours after surgery, but there was no significant difference between the two groups $(P$ value $=0.073)$. In conclusion, combination of Ibuprofen plus acetaminophen plus caffeine does not offer any clinical advantages compared with Ibuprofen for alleviating acute postoperative pain after third molar surgeries.
\end{abstract}

*Competing interests: None declared

Funding: None.

Ethical approval: Ethical approval was taken from the research and ethics committee of university.

\#Corresponding author.
Keywords: Third Molar Surgery; Pain Control; Ibuprofen; Acetaminophen; Caffeine

\section{INTRODUCTION}

Surgical removal of third molar under local anesthesia is widely carried out in general dental practice and in many surgery clinics, occupying an appreciable amount of clinical time [1]. Patients who undergo surgical extraction of impacted third molar experience intense inflammatory pain following the surgery [2], and so that many clinicians have emphasized the necessity for better pain, swelling and trismus control in patients [3]. An estimated $63.5 \%$ of the patients experience severe pain at some time during the first day [4]. For this reason, oral analgesics are provided as a standard of care for postoperative time periods for at least 24 hours [4].

The introduction of non-steroidal anti-inflammatory drugs (NSAIDs, e.g. Diclofenac potassium and Ibuprofen) has significantly altered the management of postoperative pain in dentistry and medicine. NSAIDs work well to relieve mild to moderate intense postoperative pain caused by third molar surgeries [5]. Ibuprofen is both efficacious and used extensively in the management of postoperative pain after dental surgical procedures [6]. Acetaminophen is a non-opioid analgesic with antipyretic properties, effective in relieving mild to moderate pain [7]. Although the mechanism of action is not completely understood, it is thought to act primarily through inhibition of prostaglandin synthetase in the central nervous system [8]. Acetaminophen is widely used and is very safe at the maximum total dose/day of $4 \mathrm{~g}$ [9], but does not always provide adequate pain relief on its own. It is also the analgesic of choice to be combined with NSAIDS when expected to be ineffective separately [9].

Evidence also suggests that caffeine may have an an- 
algesic effect on itself in relieving the pain [10]. On the other hand, recent studies have demonstrated that caffeine also acts as an analgesic adjuvant when combined with acetaminophen, aspirin, or their mixture [11].

Combining analgesics offers the possibility of increasing effectiveness without increasing dosage and subsequent risks [12].

The objective of this study is to compare the efficacy of a combination of Ibuprofen $200 \mathrm{mg}$ plus Acetaminophen $325 \mathrm{mg}$ plus Caffeine $40 \mathrm{mg}$ with Ibuprofen 400 $\mathrm{mg}$ alone for relieving the pain after surgical removal of impacted third molar teeth.

\section{METHODS AND MATERIALS}

80 adult patients who had at least one mandibular impacted third molar participated in a randomized, double-blind study, which had received prior ethical approval from the research and ethics committee of university.

Individuals who participated in the study were healthy (ASA Class 1 or 2 of physical status classifications) from any gender or race, ranged from 16 to 40 years old. In accordance with the Declaration of Helsinki, in 1975, written informed consent was obtained from all patients and they agreed to refrain from alcohol and sedative consumption during the postoperative period. Patients would be excluded from the study if they had a serious medical or mental condition, risk of infectious endocarditis, an acute local infection, a bleeding disorder, known sensitivity to NSAIDs, caffeine and/or acetaminophen, a history of asthma, drug or alcohol misuse, women who were pregnant or lactating, history of taking an investigational drug, or blood donation within the previous months. All of them were free of any infectious symptoms like swelling, fever, pus drainage or decreased mouth opening at the time of surgery.

The participants of the study were divided into couple of groups each including forty, in a stratified randomization manner. The medications, that is, Novafen capsules (Ibuprofen $200 \mathrm{mg}$ plus Acetaminophen $325 \mathrm{mg}$ plus Caffeine anhydrous $40 \mathrm{mg}$ ) (Brown \& Burk, Richmond, UK) and Ibuprofen $400 \mathrm{mg}$ were packed separately by the third party. The order of packing was putting ten Novafen in forty packages, and ten Ibuprofen in other forty packages in the same form and appearance. Novafen capsules is one of the common prescribed analgesic medications in Middle East and India, and also it has been used in UK.

All the packages were labeled and numbered randomly. Prior to the surgery each patient was given a package. The randomization code was concealed from study investigators, nurse, and patients and was kept in a secure location until the end of the study.
Patients in group I $(\mathrm{n}=40)$ were given Novafen and Group II $(n=40)$ consisted of patients who were just given Ibuprofen $400 \mathrm{mg}$. Preoperative analgesic drugs based on the patient's group and oral preoperative antibiotics (500 mg Amoxicillin and $250 \mathrm{mg}$ Metronidazole) were administered to all patients 30 minutes before surgery.

Preoperative pain was assessed using a Verbal Rating Scale (VRS), so that the pain was recorded as: "0-no pain", "1-mild pain" (tolerable pain), "2-moderate pain" (noticeable pain which can be relieved when patients use some kind of analgesic drugs by themselves), "3-moderate pain which cannot be relieved when patients use some kind of analgesic drugs by themselves", and "4severe pain".

All surgical procedures were performed by a single operator in a 5 months period. The operator was an oral and maxillofacial surgeon with 15 years academic and clinical experiences. Removal of all third molars were carried with buccal sulcus mucoperiosteal flap which was elevated after inferior alveolar nerve blocking with injection of two $1.8 \mathrm{ml}$ cartridge of local anesthesia (2\% lidocaine with 1:100,000 Epinephrine). After tooth extraction the site of surgery irrigated meticulously with normal saline $0.9 \%$ and then the flap was repositioned and sutured. The mean time of surgery was 20 minutes. (15 - 40 minutes).

The three categories of surgical difficulty (mild, moderate and severe) were noted by the surgeon based on the amount of bone removal and tooth sectioning, such as the operation categorized as mild trauma when tooth removal just needed a little buccal ostectomy and did not need tooth sectioning, moderate trauma when tooth removal needed to buccal and crestal ostectomy without tooth sectioning, and severe trauma when both buccal and crestal ostectomy and tooth sectioning were needed. After surgery the patients were asked not to use analgesic drug except the prepared sealed packages which were given to them randomly. They also were asked to start take their drugs 1 hour after the operation and every 6 hours after that. All patients were asked not to apply a cold compress to the surgical site after the operation because this application might affect the pain and so that the results.

Patients' pain was measured with Visual Analog Scale (VAS) after 15 minutes, 30 minutes, 1 hour, and 3 hours post operation. The patients were evaluated at 12, 24 and 48 hours post operation via telephone so that pain was assessed using a four-point categorical VRS. Data was analyzed by using SPSS for windows (v11.5, SPSS Inc., Chicago, IL) statistical software package. Mann-Witheny, student's t-test and chi-square test were used and the level of significance was set at $\mathrm{P}<0.05$. 


\section{RESULTS}

From the 80 patients who participated in the study, 73 completed the evaluation (56 females and 17 males). In group I, 36 patients were given a combination of Ibuprofen $200 \mathrm{mg}$, Acetaminophen $325 \mathrm{mg}$ and Caffeine $40 \mathrm{mg}$ and group II consisted of 37 patients who were given merely Ibuprofen $400 \mathrm{mg}$. (Figure 1)

Based on preoperative VRS, $72.6 \%$ of participants didn't have preoperative pain, $17.8 \%$ mild pain, $5.5 \%$ moderate pain and $4.1 \%$ had moderate pain which can not be relieved with medication and $0 \%$ had severe pain. (Table 1)

In this study, there was no significant relationship between preoperative pain with postoperative pain in both groups; moreover, no significant relationship between surgical trauma and postoperative pain was detected.

\subsection{Pain Analysis $15 \mathrm{~min}, 30 \mathrm{~min}, 1 \mathrm{hr}$ and $3 \mathrm{hr}$ Postoperatively}

Upon to VAS analysis, the mean postoperative pain is shown in Table 2. The mean pain measurements showed a slight numerical superiority for group I especially $3 \mathrm{hr}$ after surgery, but upon to Mann-Withney test analysis there was no statistically significant difference between two groups $(\mathrm{P}$ value $=0.073)$.

\subsection{Pain Analysis 12 hr, 24 hr and 48 hr Postoperatively}

All pain data which is shown in Table 2 were analyzed with Mann-Withney test and there was no statistically significant difference between VRS in these two groups, although in group I moderate pain which cannot be relieved with medication 12 hours and 24 hours after surgery was in a lower rate ( $\mathrm{P}$ value $>0.05)$.

The relationship between surgical trauma and postop- erative pain was analyzed with chi-square test. As it is shown in Tables $\mathbf{1}$ and 2, severe surgical trauma in group I was a little higher than group II, however, the mean pain in this group, was lower in first 3 hours after surgery without any significant statistical difference ( $\mathrm{P}$ value $>$ $0.05)$.

\section{DISCUSSION}

Impaction of the mandibular lower third molar is a common condition giving rise to symptoms which necessitate its removal. Pain, trismus, and swelling are the most common complaints occurring post-operatively [13].

After removing the impacted third molars, the pattern of postoperative pain has been reported that the intensity of pain reaches its maximum about 3 to 5 hours after the end of the operation [6,14], and it will increase between the post operative days 1 and 3, after which the symptoms subside gradually within one week [1].

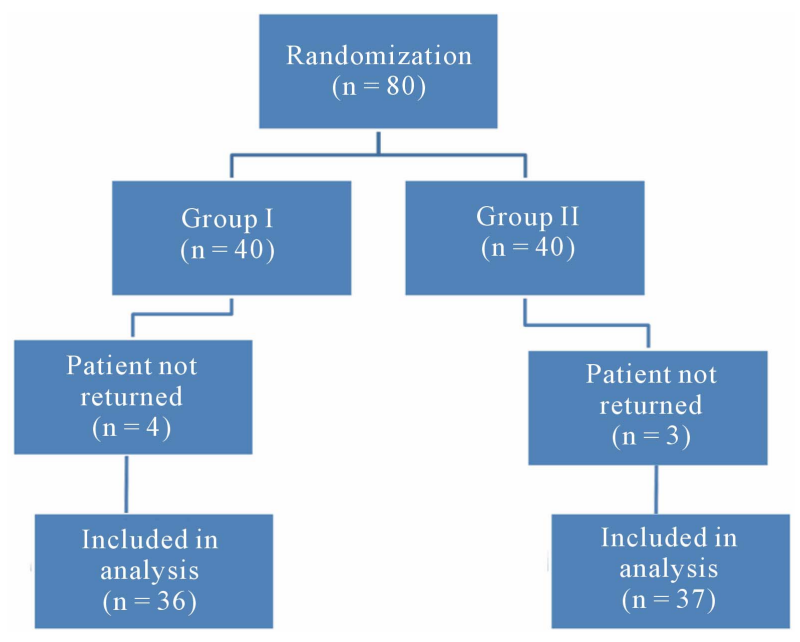

Figure 1. Flow of participants through trial.

Table 1. Characteristics of the study according to treatment group and preoperative analysis.

\begin{tabular}{|c|c|c|}
\hline Gender: n (\%) & NOVAFEN & IBUPROFEN \\
\hline - Female & $28(77.78 \%)$ & $28(75.68 \%)$ \\
\hline - male & $8(22.22 \%)$ & $9(24.32 \%)$ \\
\hline Age (y): mean (I Qrange) & $23.8(16-38)$ & $23.3(16-38)$ \\
\hline $\begin{array}{ll}\text { Preoperative pain: } \mathrm{n}(\%) \\
\text { - } & \text { No pain } \\
\text { - } & \text { Mild } \\
\text { - } & \text { Moderate } \\
\text { - } & \text { Moderate which can not be relieved with medication } \\
\text { severe }\end{array}$ & $\begin{array}{ll}- & 28(77.8 \%) \\
- & 7(19.4 \%) \\
- & 0(0 \%) \\
- & 1(5.4 \%) \\
- & 0(0 \%)\end{array}$ & $\begin{array}{ll}\text { - } & 25(67.6 \%) \\
\text { - } & 6(16.2 \%) \\
\text { - } & 4(10.8 \%) \\
\text { - } & 2(5.4 \%) \\
\text { - } & 0(0 \%)\end{array}$ \\
\hline $\begin{array}{ll}\text { Surgical trauma: n }(\%) \\
\text { - } & \text { Mild } \\
\text { - } & \text { Moderate } \\
\text { - } & \text { Severe }\end{array}$ & $\begin{array}{ll}\text { - } & 9(25 \%) \\
\text { - } & 8(22.2 \%) \\
\text { - } & 19(52.8 \%)\end{array}$ & $\begin{array}{ll}- & 12(32.4 \%) \\
- & 11(29.7 \%) \\
- & 14(37.8)\end{array}$ \\
\hline
\end{tabular}


Table 2. Postoperative pain analysis.

\begin{tabular}{|c|c|c|}
\hline & Novafen & Ibuprofen \\
\hline $\begin{array}{l}\text { VAS: } \\
\text { - } 15 \text { min post-op } \\
\text { - } 30 \text { min post-op } \\
\text { - } 1 \text { hour post-op } \\
\text { - } 3 \text { hour post-op }\end{array}$ & $\begin{array}{l}\text { - } \quad 14.5 \\
\text { - } 16.8 \\
\text { - } \quad 22.7 \\
\text { - } \quad 26.2\end{array}$ & $\begin{array}{ll}\text { - } & 15.7 \\
\text { - } & 20.4 \\
\text { - } & 25 \\
\text { - } & 39\end{array}$ \\
\hline 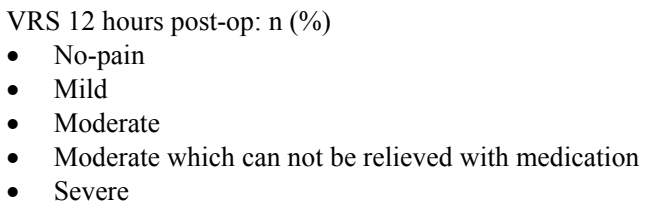 & $\begin{array}{ll}- & 0(0 \%) \\
- & 19(52.8 \%) \\
- & 14(38.9 \%) \\
- & 2(5.6 \%) \\
- & 1(2.8 \%)\end{array}$ & $\begin{array}{ll}- & 0(0 \%) \\
- & 15(40.5 \%) \\
\text { - } & 16(43.2 \%) \\
\text { - } & 4(10.8 \%) \\
\text { - } & 2(5.4 \%)\end{array}$ \\
\hline 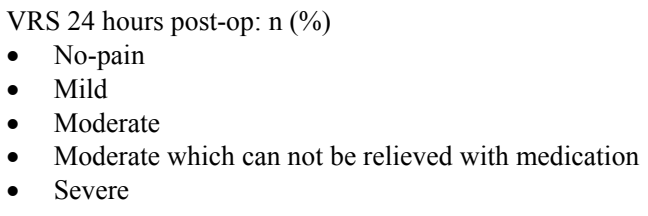 & $\begin{array}{ll}- & 0(0 \%) \\
- & 23(63.9 \%) \\
- & 9(25 \%) \\
- & 2(5.6 \%) \\
\text { - } & 2(5.6 \%)\end{array}$ & $\begin{array}{ll}- & 0(0 \%) \\
- & 17(45.9 \%) \\
\text { - } & 13(35 \%) \\
- & 6(16 \%) \\
\text { - } & 1(2.7 \%)\end{array}$ \\
\hline $\begin{array}{l}\text { VRS } 48 \text { hours post-op: } \mathrm{n}(\%) \\
\text { - } \quad \text { No-pain } \\
\text { - } \quad \text { Mild } \\
\text { - } \\
\text { - Moderate } \\
\text { - }\end{array}$ & $\begin{array}{ll}- & 0(0 \%) \\
- & 24(66.7 \%) \\
- & 9(25 \%) \\
-\quad & 2(5.6 \%) \\
- & 1(2.8 \%)\end{array}$ & $\begin{array}{ll}- & 0(0 \%) \\
\text { - } & 23(62.2 \%) \\
\text { - } & 10(27 \%) \\
\text { - } & 2(5.4 \%) \\
\text { - } & 2(5.4 \%)\end{array}$ \\
\hline
\end{tabular}

One technique that has been proposed for the reduction of postoperative inflammation is to control the synthesis of prostaglandins. Prostaglandins play a major role in the induction of pain, inflammation, and fever. The reduction of biosynthesis of prostaglandins by inhibition of the cyclo-oxygenase enzyme system is considered an important mechanism of action of NSAIDs. When administered preoperatively, NSAIDs have shown to be particularly effective in combating postoperative pain [14]. Ibuprofen is ranked as an NSAID, thereby indicating an "anti-inflammatory" effect [15]. Dionne and Cooper [16] reported on a placebo-controlled study in which the principle objective was to determine whether preoperative treatment with Ibuprofen $400 \mathrm{mg}$ could delay the onset and reduce the severity of pain after third molar removal. Their findings showed that a single dose of Ibuprofen $400 \mathrm{mg}$, when compared with placebo, delayed the mean time of onset of post-operative pain by $100 \mathrm{~min}$.

Well known adverse effects of Ibuprofen are such as: nausea, gastrointestinal bleeding, raised liver enzymes, diarrhea, constipation, epistaxis, headache, dizziness, rash, salt and fluid retention, and hypertension [17]. As with other NSAIDs, ibuprofen has been reported to be a photosensitising agent and also has been implicated in increasing the risk of myocardial infarction particularly in whom using high doses chronically [18].

On the other hand, Acetaminophen is an aniline derivative with both analgesic and anti-pyretic properties. It is one of the most common drugs used in the world and has a very similar structure to aspirin and because of this they are recognized by the same enzyme which is responsible for biosynthesis of prostaglandins [19]. Reduction of the amount of prostaglandin, therefore, helps prevent pain, and also used for the reduction of fever of bacterial or viral origin [20]. Various studies have been carried out to evaluate the efficacy of paracetamol in postoperative pain after third molar removal [13].

Prolonged daily use of Acetaminophen increases the risk of liver damage and upper gastrointestinal complications. As the Paracetamol is metabolized by the liver and is hepatotoxic, so that combination of Acetaminophen and Ibuprofen could be hepatotoxic too [21]. Chronic users of acetaminophen may have a higher risk of developing blood cancer [22].

Caffeine is mainly ingested by drinking coffee, colabeverages, and tea to act both as diuretic and as stimulant to the central nervous and to the cardiovascular systems [23]. Because caffeine is both water-soluble and lipidsoluble, therefore, it crosses the blood-brain barrier and acts as a nonselective antagonist of adenosine receptors and reduces the effects of adenosine in brain. The structure of caffeine molecule is similar to adenosine, acting as a competitive inhibitor; it can bind to adenosine receptors on the surface of cells without activating them [24].

Codeine belongs to the group of centrally acting analgesics known as the opioids. Opioids interact with receptors scattered throughout the C.N.S. Although there has not been a specific study to evaluate the efficacy of 
codeine in post-operative pain after third molar surgery, some studies have included codeine phosphate as a reference, or standard drug in their design [13]. Cooper et al. [25] investigated the efficacy of paracetamol and oxycodone in 298 patients after third molar surgery. The authors concluded that the combination of paracetamol and oxycodone was effective for treating postoperative pain after third molar surgery, but an increase in unwanted side effects was noted with the high dose combination.

The use of the mixture of paracetamol and caffeine as an analgesic and antipyretic is well established in pharmaceutical formulation [26]. In order to achieve better curative effect and lower toxicity, it is very important to control the content of paracetamol and caffeine in pharmaceutical tablets [27]. On the other hand Mitchell A. et al. [28] suggested that a combination of Acetaminophen and Ibuprofen, is a safe and effective strategy. In our trial we used a combination of Ibuprofen $200 \mathrm{mg}$, Acetaminophen $325 \mathrm{mg}$ plus Caffeine $40 \mathrm{mg}$. It is clear that the side effects of this combination may include the side effects of all the aforementioned drugs, however, we did not investigate on the side effects in this study. We did not use any as-needed dosing of either analgesic regime tested within our trial design, because it appears to be substandard to regular dosing in randomized trials [28].

In the present trial, although severe surgical trauma and some VAS measurements showed a slight numerical superiority for a combination of Ibuprofen $200 \mathrm{mg}$, Acetaminophen $325 \mathrm{mg}$ plus Caffeine $40 \mathrm{mg}$ especially 3hours after surgery, there was no statistically significant difference between two groups. As a result, we prefer to emphasize on our data as not demonstrating an analgesic benefit of Novafen over Ibuprofen and base on statistic analysis, combination therapy (Novafen) failed to exert greater analgesic effects than Ibuprofen alone in traditional doses. This finding contrasts with Mitchell A. et al. [28] who reported better results with combination therapy, and also in contrast with Merry A. F. et al. [9] who concluded that using the combination of acetaminophen and ibuprofen is more effective in pain relieve during the first $48 \mathrm{~h}$ after oral surgery than using the same daily dosage of either agent alone .

In conclusion, it can be grasped from the current study that the administration of a combination of Ibuprofen plus Acetaminophen plus Caffeine does not offer any clinical advantages compared with Ibuprofen for alleviating acute postoperative pain after third molar surgeries.

\section{REFERENCES}

[1] Babatunde, O.B., Jelili, A.A., Wasiu, L.A., Akinola, L.L., Godwin, T.A. and Mobolanle, O.O. (2005) Effects of co-administered dexamethasone and diclofenac potassium on pain, swelling and trismus following third molar surgery. Head \& Face Medicine, 7, 1-11. doi:10.1186/1746-160X-1-11

[2] Conrad, S.M., Blakey, G.H., Shugars, D.A., et al. (1999) Patient's perception of recovery after third molar surgery. Journal of Oral and Maxillofacial Surgery, 57, 12881294. doi:10.1016/S0278-2391(99)90861-3

[3] Tiwana, P.S., Foy, S.P., Shugars, D.A., Marciani, R.D., Conrad, S.M., Phillips, C. and White, R.P. (2005) The impact of intravenous corticosteroid with third molar surgery in patients at high risk for delayed health-related quality of life and clinical recovery. Journal of Oral and Maxillofacial Surgery, 63, 55-62. doi:10.1016/j.joms.2004.01.029

[4] Zuniga, J.R., Phillips, C.L., Shugars, D., Lyon, J.A., Peroutka, S.J., Swarbrick, J., Bon, C. (2004) Analgesic safety and efficacy of diclofenac sodium softgels on postoperative third molar extraction pain. Journal of Oral and Maxillofacial Surgery, 62, 806-815.

doi:10.1016/j.joms.2003.12.019

[5] Cooper, S.A. and Beaver, W.T. (1976) A model to evaluate mild analgesics in oral surgery outpatients. Clinical Pharmacology \& Therapeutics, 20, 241-250.

[6] Seymour, R.A., Ward-Booth, P. and Kelly, P.J. (1996) Evaluation of different doses of soluble ibuprofen and ibuprofen tablets in postoperative dental pain. British Journal of Oral and Maxillofacial Surgery, 34, 110-114. doi:10.1016/S0266-4356(96)90147-3

[7] Moore, A., Collins, S., Carroll, D., McQuay, H. and Edwards, J. (2000) Single dose paracetamol (acetaminophen), with and without codeine, for postoperative pain. Cochrane Database of Systematic Reviews, 2, CD001547.

[8] Rang, H.P., Dale, M.M. and Ritter, J.M. (1999) Antiinflammatory and immunosuppresant drugs. Pharmacology, 4th Edition, Churchill Livingstone, Edinburgh, 229247.

[9] Merry, A.F., Gibbs, R.D., Edwards, J., Ting, G.S., Frampton, C., Davies, E. and Anderson, B.J. (2010) Combined acetaminophen and ibuprofen for pain relief after oral surgery in adults: A randomized controlled trial. British Journal of Anaesthesia, 104, 80-88. doi:10.1093/bja/aep338

[10] Diamond, S. and Freitag, F.G. (2001) The use of ibuprofen plus caffeine to treat tension-type headache. Current Pain and Headache Reports, 5, 472-478.

[11] Forbes, J.A., Beaver, W.T., Jones, K.F., Kehm, C.J., Smith, W.K., Gongloff, C.M., Zeleznock, J.R. and Smith, J.W. (1991) Effect of caffeine on ibuprofen analgesia in postoperative oral surgery pain. Clinical Pharmacology \& Therapeutics, 49, 674-684. doi:10.1038/clpt.1991.85

[12] Desmeules, J., Rollason, V., Piguet, V. and Dayer, P. (2003) Clinical pharmacology and rationale of analgesic combinations. European Journal of Anaesthesiology, 20, 7-11.

[13] Seymour, R.A. and Walton, J.G. (1984) Pain control after third molar surgery. International Journal of Oral Surgery, 13, 457-485. doi:10.1016/S0300-9785(84)80017-4 
[14] Fisher, S.E., Frame, J.W., Rout, P.G.J. and McEntegart, D.J. (1988) Factors affecting the onset and severity of pain following the surgical removal of unilateral impacted third molar teeth. British Dental Journal, 164, 351-354. doi:10.1038/sj.bdj.4806453

[15] Bjørnsson, G.A., Haanaes, H.R. and Skoglund, L.A. (2003) A randomized, double-blind crossover trial of paracetamol $1000 \mathrm{mg}$ four times daily vs ibuprofen 600 mg: effect on swelling and other postoperative events after third molar surgery. British Journal of Clinical Pharmacology, 55, 405-412. doi:10.1046/j.1365-2125.2003.01779.x

[16] Dionne, R.A. and Cooper, S.A. (1978) Evaluation of preoperative ibuprofen for post-operative pain after removal of 8/8. Journal of Oral Surgery, 45, 851-856.

[17] Geisslinger, G., Dietzel, K., Bezler, H., Nuernberg, B., Brune, K. (1989) Therapeutically relevant differences in the pharmacokinetical and pharmaceutical behavior of ibuprofen lysinate as compared to ibuprofen acid. International Journal of Clinical Pharmacology, Therapy and Toxicology, 27, 324-328.

[18] Bergner, T. and Przybilla, B. (1992) Photosensitization caused by ibuprofen. Journal of the American Academy of Dermatology, 26, 114-116. doi:10.1016/0190-9622(92)70018-B

[19] Knochen, M., Giglio, J. and Reis, B.F. (2003) Flow-injection spectrophotometric determination of paracetamol in tablets and oral solutions. Journal of Pharmaceutical and Biomedical Analysis, 33, 191-197. doi:10.1016/S0731-7085(03)00342-X

[20] Rodenas, V., García, M.S., Sánchez-Pedreño, C. and Albero, M.I. (2000) Simultaneous determination of propacetamol and paracetamol by derivative spectrophotometry. Talanta, 52, 517-523. doi:10.1016/S0039-9140(00)00397-0

[21] Garcia Rodríguez, L.A. and Hernández-Díaz, S. (2001) The risk of upper gastrointestinal complications associated with nonsteroidal anti-inflammatory drugs, glucocorticoids, acetaminophen, and combinations of these agents. Arthritis Research, 3, 98-101. doi:10.1186/ar146

[22] Walter, R.B., Milano, F., Brasky, T.M. and White, E. (2011) Long-term use of acetaminophen, aspirin, and other nonsteroidal anti-inflammatory drugs and risk of hematologic malignancies: results from the prospective Vitamins and Lifestyle (VITAL) study. Journal of Clinical Oncology, 29, 2424-2431. doi:10.1200/JCO.2011.34.6346

[23] Zen, J.M., Ting, Y.S. and Shih, Y. (1998) Voltammetric determination of caffeine in beverages using a chemically modified electrode. Analyst, 123, 1145-1147. doi:10.1039/a708360b

[24] Fisone, G., Borgkvist, A. and Usiello, A. (2004) Caffeine as a psychomotor stimulant: Mechanism of action. Cellular and Molecular Life Sciences, 61, 857-872. doi:10.1007/s00018-003-3269-3

[25] Cooper, S.A., Precheur, H., Rauch, D., Rosenheck, A., Ladov, M. and Engel, J. (1980) Evaluation of oxycodone and acetaminophen in treatment of postoperative dental pain. Oral Surgery, Oral Medicine, Oral Pathology, 50, 496-501. doi:10.1016/0030-4220(80)90430-2

[26] Dinç, E. (1999) A comparative study of the ratio spectra derivative spectrophotometry, Vierordt's method and high-performance liquid chromatography applied to the simultaneous analysis of caffeine and paracetamol in tablets. Journal of Pharmaceutical and Biomedical Analysis, 21, 723-730. doi:10.1016/S0731-7085(99)00186-7

[27] Safavi, A. and Tohidi, M. (2007) Simultaneous kinetic determination of levodopa and carbidopa by H-point standard addition method. Journal of Pharmaceutical and Biomedical Analysis, 44, 313-318. doi:10.1016/j.jpba.2007.02.020

[28] Mitchell, A., Van Zanten, S.V., Inglis, K. and Porter, G. (2008) A randomized controlled trial comparing acetaminophen plus ibuprofen versus acetaminophen plus codeine plus caffeine after outpatient general surgery. Journal of the American College of Surgeons, 206, 472 479. doi:10.1016/j.jamcollsurg.2007.09.006 